\title{
A Rare Complication After Laparoscopic Lateral Lymph Node Dissection for Rectal Cancer: Two Case Reports of Internal Hernia Below the Superior Vesical Artery
}

\author{
Daichi Kitaguchi, Yuji Nishizawa, Takeshi Sasaki, Yuichiro Tsukada, Akihiro Kondo, Hiro Hasegawa and Masaaki Ito \\ Department of Colorectal Surgery, National Cancer Center Hospital East, Chiba, Japan
}

\begin{abstract}
:
Total mesorectal excision or mesorectal excision with lateral lymph node dissection (LLND) is a standard treatment for locally advanced lower rectal cancer in Japan. Although laparoscopic LLND for rectal cancer is technically complex and challenging, previous studies have demonstrated its feasibility, and the procedure is gradually becoming more common. With this increased use, the incidence of new complications specific to laparoscopic LLND is likely to increase, and a greater awareness of these complications is required. Here we report two cases of internal hernia of the small bowel through an orifice of the vesicohypogastric fascia below the superior vesical artery after laparoscopic LLND. There are six previous reports of internal hernia underneath the pelvic blood vessel after pelvic lymph node dissection for urological or gynecological malignancies, but our cases are the first two that occurred after LLND for rectal cancer. Almost all cases, including our two cases, occurred after laparoscopic surgery and required resection of an incarcerated small bowel. Therefore, the incidence of this complication is likely to increase as the number of cases treated with laparoscopic LLND increases. Our cases show that it is important to perform an emergency operation promptly instead of conservative treatment.
\end{abstract}

Keywords:

lateral lymph node dissection, internal hernia, rectal cancer, postoperative complications

J Anus Rectum Colon 2018; 2(3): 110-114

\section{Introduction}

The standard treatment for locally advanced lower rectal cancer internationally is total mesorectal excision (TME) or mesorectal excision (ME) with neoadjuvant chemoradiotherapy (NACRT), but the standard treatment for locally advanced lower rectal cancer in Japan is TME or ME with lateral lymph node dissection (LLND) ${ }^{1)}$. In a retrospective multicenter study, Sugihara et al. found that the risk of local recurrence was reduced by $50.3 \%$ and the 5-year survival rate improved by $8.0 \%$ after LLND in patients with pT3/T4 lower rectal cancer ${ }^{2}$. Moreover, a randomized controlled trial (Japan Clinical Oncology Group Study, JCOG0212) comparing ME with or without LLND for stage II to III lower rec- tal cancer showed that ME with LLND resulted in lower rates of local recurrence, especially in the lateral pelvis, compared with ME alone ${ }^{3)}$.

Laparoscopic LLND for rectal cancer is a technically complex and challenging procedure; however, its feasibility has been demonstrated ${ }^{1,4)}$, and it is gradually becoming more common. This is likely to increase the incidence of new complications specific to laparoscopic LLND, and a greater awareness of these complications is needed. Here, we report two cases of internal hernia of the small bowel through an orifice of the vesicohypogastric fascia below the superior vesical artery (SVA) after laparoscopic LLND. 

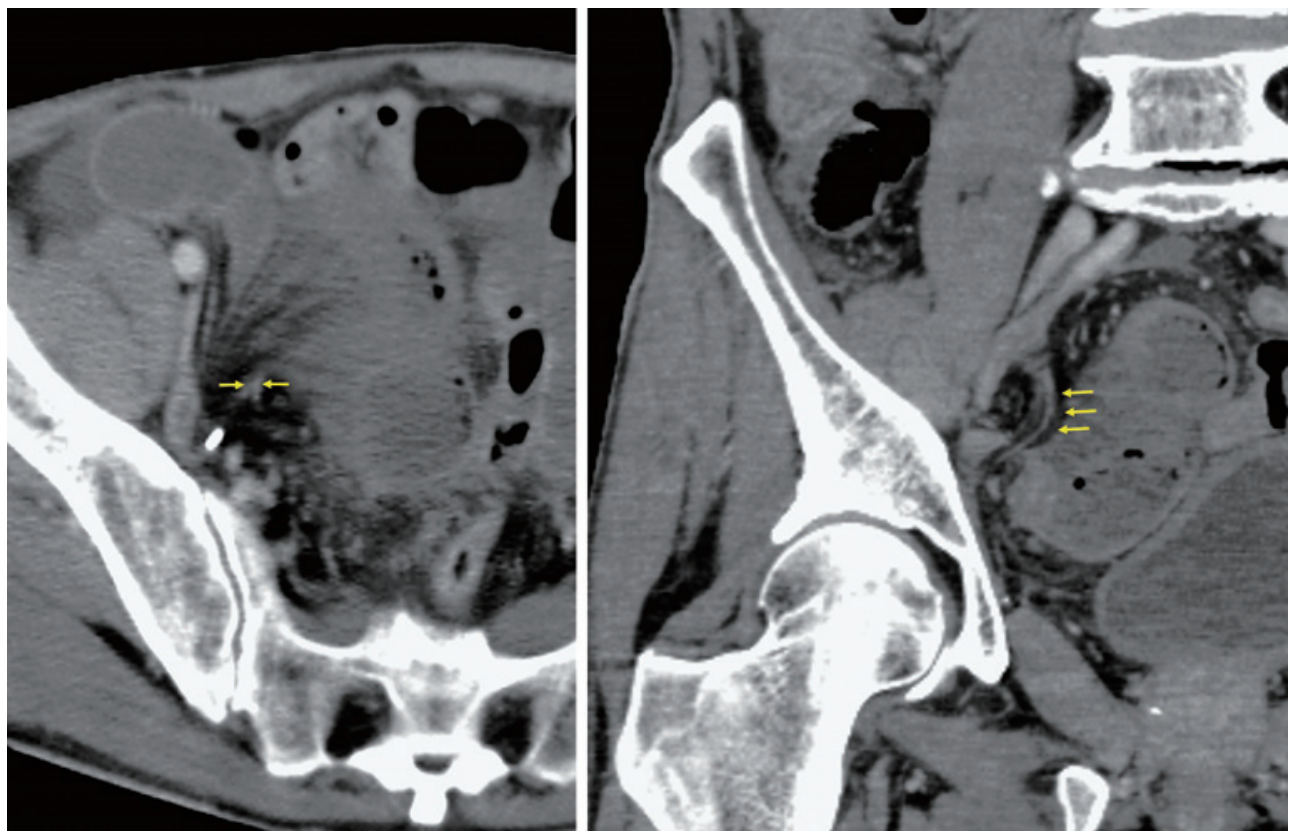

Figure 1. Case 1. Contrast-enhanced CT revealed a caliber change of the small bowel located just to the caudal-dorsal side of the right SVA (arrow).

\section{Case Reports}

Case 1: A 68-year-old male was diagnosed with rectal cancer of clinical stage II. The tumor was located below the peritoneal reflection. In accordance with the Japanese Society for Cancer of the Colon and Rectum (JSCCR) Guidelines for Treatment of Colorectal Cancer, the patient underwent laparoscopic super low anterior resection and laparoscopic LLND.

LLND was performed in accordance with reported methods $^{5}$. The ureter was isolated and displaced away from the LLND side. The border between the internal iliac vessels and the obturator lymph nodes was separated, and then extended to the border of adipose tissues surrounding the urinary bladder and led to the stratum disjuncture extending from the pelvic wall. The lateral surface of the internal pudendal artery was exfoliated to Alcock's canal, and the sacral nerves and coccygeal muscle were exposed. Obturator nerves were preserved. The lateral side of the obturator space was exposed to the pelvic wall along the obturator fascia, and the inside of the pelvic wall was dissected to the lateral side of the internal iliac artery. The proximal side was dissected en bloc to the bifurcation of the internal and external iliac artery. The internal iliac lymph nodes, which are located between the internal iliac artery and the autonomic nerves (pelvic splanchnic nerves and pelvic plexus), were dissected. The umbilical artery and vesical arteries and veins were preserved.

Four months after the initial surgery, the patient was admitted to our hospital with a chief complaint of mild upper abdominal pain. Contrast-enhanced computed tomography (CT) revealed a caliber change of the small bowel in the right lateral pelvic cavity (Figure 1). There were no findings of ischemia of the small bowel, but an emergency ileus operation was performed because a massive ascites was apparent. Intraoperative findings showed internal herniation of the small bowel through an orifice of the right vesicohypogastric fascia below the right SVA. The incarcerated small bowel was necrotic and required resection of a length of 40 $\mathrm{cm}$. We considered transection of the right SVA to prevent recurrence of the internal hernia, but this was not done because the right SVA was attached to the right obturator nerve. The postoperative course was uneventful, and the patient was discharged on postoperative day 12 .

Case 2: A 59-year-old male was diagnosed with rectal cancer of clinical stage III. The tumor was located below the peritoneal reflection. In accordance with the JSCCR Guidelines for Treatment of Colorectal Cancer, the patient underwent laparoscopic intersphincteric resection and laparoscopic LLND. The surgical procedure for LLND was the same as that in case 1 . Two months after the initial surgery, the patient was admitted to our hospital with chief complaints of nausea and abdominal pain, which had persisted for 1 week. Contrast-enhanced CT revealed a caliber change of the small bowel in the right lateral pelvic cavity (Figure 2). There were no findings of ischemia of the small bowel, but internal hernia underneath the pelvic blood vessel was suspected, and an emergency laparoscopic ileus operation was performed. Intraoperative findings showed internal herniation of the small bowel through an orifice of the right vesicohy- 


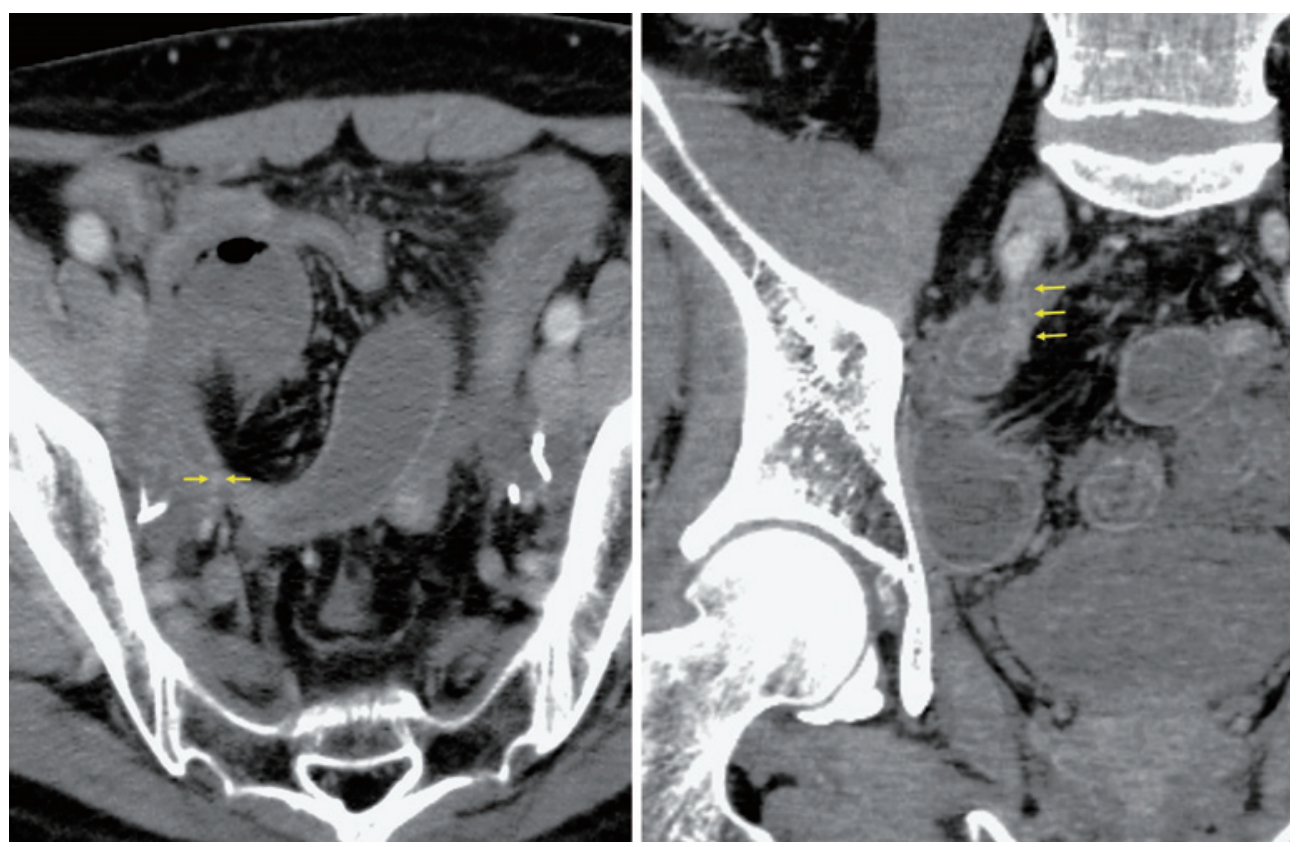

Figure 2. Case 2. Contrast-enhanced CT revealed a caliber change of the small bowel located just to the caudal-dorsal side of the right SVA (arrow).

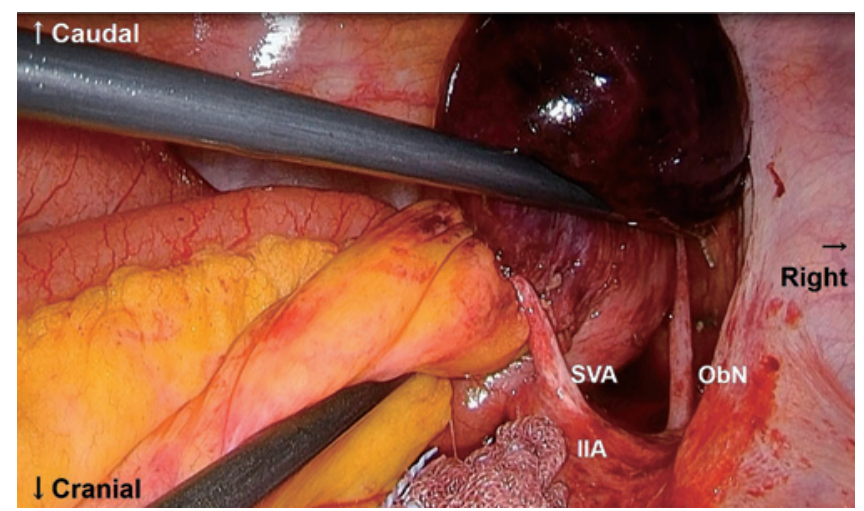

Figure 3. Case 2. Intraoperative findings showed internal herniation of the small bowel through an orifice of the right vesicohypogastric fascia below the right SVA. SVA: superior vesical artery; IIA: internal iliac artery; ObN: obturator nerve.

pogastric fascia below the right SVA, as in case 1 (Figure $3)$. The incarcerated small bowel was highly congested and required resection of a length of $15 \mathrm{~cm}$. The right SVA was transected to prevent recurrence of the internal hernia. The postoperative course was uneventful, and the patient was discharged on postoperative day 11 .

\section{Discussion}

In a retrospective multicenter study in Japan, the incidence of lateral pelvic lymph node metastasis in patients with T3 or T4 lower rectal cancer was $18.1 \%{ }^{2}$. The 2014 JSCCR Guidelines for Treatment of Colorectal Cancer list
TME or ME with LLND as the standard procedure for lower rectal cancer in Japan ${ }^{6}$. In the JCOG0212 study, the noninferiority of ME alone to ME with LLND could not be confirmed, and LLND was found to reduce local recurrence, especially in the lateral pelvis. These findings supported the efficacy of ME with LLND for lower rectal cancer, defined as a tumor with the lower margin below the peritoneal reflection, including clinical stage II/III tumors ${ }^{3)}$.

Some previous studies have shown the feasibility of laparoscopic LLND for rectal cancer. In a multicenter retrospective cohort study, Yamaguchi et al. compared laparoscopic LLND with open LLND and concluded that laparoscopic LLND is safe and feasible and is associated with oncological outcomes similar to those of open LLND ${ }^{1)}$. Ogura et al. reported that additional laparoscopic LLND is feasible in patients with advanced lower rectal cancer and clinically swollen LLNs treated with NACRT, with no significant increase in major complications compared with TME alone ${ }^{4)}$. Based on such accumulated evidence, laparoscopic LLND has gradually been accepted as a safe and feasible procedure for rectal cancer in recent years. Additional prospective, randomized controlled trials are necessary to confirm the longterm oncological outcome and the feasibility.

Laparoscopic gastrectomy is widely used as a treatment option for gastric cancer, but internal hernia may occur as a result of postoperative small-bowel obstruction, particularly after Roux-en-Y reconstruction; in contrast, more adhesions occur after open gastrectomy ${ }^{7}$. Hiki et al. reported significantly more postoperative intra-abdominal adhesions in open surgery than in laparoscopic surgery ${ }^{8}$. Typical compli- 
Table 1 Previous Reports of Internal Hernia Underneath the Pelvic Blood Vessel after Pelvic LLND.

\begin{tabular}{|c|c|c|c|c|c|c|c|}
\hline $\begin{array}{l}\text { Age, } \\
\text { Sex }\end{array}$ & Initial diagnosis & Initial operation & $\begin{array}{l}\text { Interval } \\
\text { between two } \\
\text { operations }\end{array}$ & Chief complaint & $\begin{array}{l}\text { Orifice of } \\
\text { herniation }\end{array}$ & $\begin{array}{l}\text { Required } \\
\text { small-bowel } \\
\text { resection }\end{array}$ & Discharge \\
\hline $52, \mathrm{M}$ & $\begin{array}{l}\text { Right testicular } \\
\text { teratocarcinoma }\end{array}$ & $\begin{array}{l}\text { Radical retroperitoneal } \\
\text { lymphadenectomy after } \\
\text { orchiectomy }\end{array}$ & 3 months & $\begin{array}{l}\text { Abdominal pain, } \\
\text { nausea, vomiting }\end{array}$ & $\begin{array}{l}\text { Right common } \\
\text { iliac artery }\end{array}$ & Yes & POD66 \\
\hline $67, \mathrm{~F}$ & Cervical cancer & $\begin{array}{l}\text { Laparoscopic radical hysterec- } \\
\text { tomy, and bilateral salpingo- } \\
\text { oophorectomy with pelvic } \\
\text { lymphadenectomy }\end{array}$ & $\begin{array}{l}\text { Several } \\
\text { months }\end{array}$ & Abdominal pain & $\begin{array}{l}\text { Right external } \\
\text { iliac artery }\end{array}$ & Yes & POD9 \\
\hline $56, \mathrm{~F}$ & $\begin{array}{l}\text { Right ovarian } \\
\text { cancer }\end{array}$ & $\begin{array}{l}\text { Bilateral salpingo-oophorecto- } \\
\text { my, total abdominal hysterec- } \\
\text { tomy, omentectomy, appen- } \\
\text { dectomy with radical } \\
\text { retroperitoneal lymphadenec- } \\
\text { tomy }\end{array}$ & 4 years & $\begin{array}{l}\text { Abdominal pain, } \\
\text { vomiting, } \\
\text { inability to pass } \\
\text { gas or stools }\end{array}$ & $\begin{array}{l}\text { Left external } \\
\text { iliac artery }\end{array}$ & No & POD1 \\
\hline $39, \mathrm{~F}$ & Cervical cancer & $\begin{array}{l}\text { Laparoscopic trachelectomy } \\
\text { with pelvic lymphadenectomy }\end{array}$ & 2 years & $\begin{array}{l}\text { Abdominal pain, } \\
\text { nausea, vomiting }\end{array}$ & $\begin{array}{l}\text { Right common } \\
\text { iliac artery }\end{array}$ & Yes & POD6 \\
\hline $50, \mathrm{M}$ & Bladder cancer & $\begin{array}{l}\text { Robot-assisted laparoscopic } \\
\text { partial cystectomy with extend- } \\
\text { ed pelvic lymphadenectomy }\end{array}$ & 5 months & $\begin{array}{l}\text { Abdominal pain, } \\
\text { nausea, vomiting }\end{array}$ & $\begin{array}{l}\text { Right common } \\
\text { iliac artery }\end{array}$ & Yes & Not listed \\
\hline $50, \mathrm{M}$ & Prostate cancer & $\begin{array}{l}\text { Robot-assisted laparoscopic } \\
\text { prostatectomy with extended } \\
\text { pelvic lymph node dissection }\end{array}$ & 1 year & Abdominal pain & $\begin{array}{l}\text { Left external } \\
\text { iliac artery }\end{array}$ & Yes & POD13 \\
\hline $68, \mathrm{M}$ & Rectal cancer & $\begin{array}{l}\text { Laparoscopic super low } \\
\text { anterior resection with lateral } \\
\text { lymph node dissection }\end{array}$ & 4 months & $\begin{array}{l}\text { Upper abdominal } \\
\text { pain }\end{array}$ & $\begin{array}{l}\text { Right superior } \\
\text { vesical artery }\end{array}$ & Yes & POD12 \\
\hline $59, \mathrm{M}$ & Rectal cancer & $\begin{array}{l}\text { Laparoscopic intersphincteric } \\
\text { resection with lateral lymph } \\
\text { node dissection }\end{array}$ & 2 months & $\begin{array}{c}\text { Abdominal pain, } \\
\text { nausea }\end{array}$ & $\begin{array}{l}\text { Right superior } \\
\text { vesical artery }\end{array}$ & Yes & POD11 \\
\hline
\end{tabular}

cations of LLND include lymphocele, pelvic hematoma, and deep-vein thrombosis. An internal hernia is rarely seen after open LLND because postoperative intra-abdominal adhesion prevents internal herniation in the lateral pelvic cavity. However, in systematic laparoscopic LLND, an orifice of the vesicohypogastric fascia is formed behind the preserved SVA, and internal hernia of the small bowel through the orifice may occur if there is slight postoperative intraabdominal adhesion. We performed LLND for 476 cases in our department from January 2010 to October 2017: 200 cases using open LLND and 276 cases with laparoscopic LLND. The morbidity of internal hernia in the lateral pelvic cavity was $0.7 \%(2 / 276)$ in the laparoscopic group, whereas this complication did not occur in the open group. Therefore, internal hernia may be specific to laparoscopic LLND.

We searched the PubMed database using the key words "internal hernia," "pelvis (or pelvic)," and "artery" and found six case reports of internal hernia underneath the pelvic blood vessel after pelvic LLND (Table 1) ${ }^{9-14)}$. In these six reports, three cases occurred after urological surgery and three after gynecological surgery. Therefore, our cases are the first two reports of this condition after LLND for rectal cancer. In six of eight cases, including our two cases, internal hernia underneath the pelvic blood vessel occurred after laparoscopic surgery. There is a possibility that internal hernia underneath the SVA will increase in future as the number of cases treated with laparoscopic LLND increases.

When signs and symptoms of small-bowel obstruction occur after surgery, the most common reason is adhesive ileus ${ }^{15}$. Therefore, after laparoscopic LLND, it is important to distinguish internal hernia below the SVA from adhesive ileus. Symptoms do not distinguish these two diseases because they are nonspecific, but contrast-enhanced CT is useful for this purpose. The most characteristic CT finding is the caliber change of the small bowel located at the caudaldorsal side of the SVA, and this finding is more easily detectable in the coronal plane of CT (Figure 1, 2). Ischemic change of the small bowel is barely observed in contrastenhanced CT because an orifice of the vesicohypogastric fascia formed after LLND is relatively wide, and seven of eight cases of internal hernia underneath the pelvic blood vessel required resection of the incarcerated small bowel (Table 1). Therefore, an emergency operation is required instead of conservative treatment. In our cases, the SVA was transected to prevent recurrence of internal hernia in case 2 . This was not done in case 1 because the SVA was adhered to the obturator nerve. If organ perfusion and nerve function are not affected, transection of the SVA and opening of the 
hernia orifice may be useful to prevent recurrence.

In conclusion, after systematic laparoscopic LLND, there is a risk of internal herniation of the small bowel through an orifice of the vesicohypogastric fascia below the SVA. The incidence of this complication is expected to increase as the number of cases of laparoscopic LLND increases. When this complication is suspected, it is important to distinguish it from adhesive ileus and to perform an emergency operation promptly.

\section{Conflicts of Interest}

There are no conflicts of interest.

\section{References}

1. Yamaguchi T, Konishi T, Kinugasa Y, et al. Laparoscopic versus open lateral lymph node dissection for locally advanced low rectal cancer: a subgroup analysis of a large multicenter cohort study in Japan. Dis Colon Rectum. 2017 Sep; 60(9): 954-64.

2. Sugihara K, Kobayashi H, Kato T, et al. Indication and benefit of pelvic side wall dissection for rectal cancer. Dis Colon Rectum. 2006 Nov; 49(11): 1663-72.

3. Fujita S, Mizusawa J, Kanemitsu Y, et al. Colorectal Cancer Study Group of Japan Clinical Oncology Group. Mesorectal excision with or without lateral lymph node dissection for clinical stage II/ III lower rectal cancer (JCOG0212): A multicenter, randomized controlled, noninferiority trial. Ann Surg. 2017 Aug; 266(2): 2017.

4. Ogura A, Akiyoshi T, Nagasaki T, et al. Feasibility of laparoscopic total mesorectal excision with extended lateral pelvic lymph node dissection for advanced lower rectal cancer after preoperative chemoradiotherapy. World J Surg. 2017 Mar; 41(3): 868-75.

5. Moriya Y, Sugihara K, Akasu T, et al. Importance of extended lymphadenectomy with lateral node dissection for advanced lower rectal cancer. World J Surg. 1997 Sep; 21(7): 728-32.

6. Watanabe T, Itabashi M, Shimada Y, et al. Japanese Society for
Cancer of the Colon and Rectum (JSCCR) Guidelines 2014 for treatment of colorectal cancer. Int J Clin Oncol. 2015 Apr; 20(2): 207-39.

7. Kimura H, Ishikawa M, Nabae $T$, et al. Internal hernia after laparoscopic gastrectomy with Roux-en-Y reconstruction for gastric cancer. Asian J Surg. 2017 May; 40(3): 203-9.

8. Hiki N, Shimizu N, Yamaguchi H, et al. Manipulation of the small intestine as a cause of the increased inflammatory response after open compared with laparoscopic surgery. Br J Surg. 2006 Feb; 93 (2): 195-204.

9. Guba AM Jr, Lough F, Collins GJ, et al. Iatrogenic internal hernia involving the iliac artery. Ann Surg. 1978 Jul; 188(1): 49-52.

10. Kim KM, Kim CH, Cho MK, et al. A strangulated internal hernia behind the external iliac artery after a laparoscopic pelvic lymphadenectomy. Surg Laparosc Endosc Percutan Tech. 2008 Aug; 18(4): 417-9.

11. Dumont KA, Wexels JC. Laparoscopic management of a strangulated internal hernia underneath the left external iliac artery. Int J Surg Case Rep. 2013; 4(11): 1041-3.

12. Ardelt M, Dittmar Y, Scheuerlein H, et al. Post-operative internal hernia through an orifice underneath the right common iliac artery after Dargent's operation. Hernia. 2014; 18(6): 907-9.

13. Pridjian A, Myrick S, Zeltser I. Strangulated internal hernia behind the common iliac artery following pelvic lymph node dissection. Urology. 2015 Nov; 86(5): e23-4.

14. Viktorin-Baier P, Randazzo M, Medugno $C$, et al. Internal hernia underneath an elongated external iliac artery: A complication after extended pelvic lymphadenectomy and robotic-assisted laparoscopic prostatectomy. Urol Case Rep. 2016 Sep; 8: 9-11.

15. van Oudheusden TR, Aerts BA, de Hingh IH, et al. Challenges in diagnosing adhesive small bowel obstruction. World J Gastroenterol. 2013 Nov; 19(43): 7489-93.

Journal of the Anus, Rectum and Colon is an Open Access article distributed under the Creative Commons Attribution-NonCommercial-NoDerivatives 4.0 International License. To view the details of this license, please visit (https://creativec ommons.org/licenses/by-nc-nd/4.0/). 